\title{
Effects of Size and Prestressing of Aluminum Particles on the Oxidation of Levitated exo-Tetrahydrodicyclopentadiene Droplets
}

Michael Lucas, ${ }^{1, \S}$ Stephen J. Brotton, ${ }^{1, \S}$ Ahreum Min, ${ }^{1}$ Connor Woodruff, ${ }^{2}$ Michelle L. Pantoya, ${ }^{2}$ Ralf I. Kaiser ${ }^{1 *}$

${ }^{1}$ Department of Chemistry, University of Hawai'i at Manoa, Honolulu, HI 96822

${ }^{2}$ Mechanical Engineering Department, Texas Tech University, Lubbock, TX 79409

\section{Corresponding Author}

*Email: ralfk@hawaii.edu

\section{Author Contributions}

${ }^{\S}$ S.J.B. and M.L. contributed equally to this work. 


\section{Optical Model for the Propagation of a Carbon-Dioxide-Laser Beam Through a JP-10 Droplet Containing Al Particles}

An optical model is developed below to describe the propagation of a carbon-dioxide-laser beam through a JP-10 droplet containing Al particles. First, we will determine the absorption coefficient $\alpha$ defined by

$$
I=I_{0} e^{-\alpha l}
$$

for transmission through pure JP-10 at the wavelength of the $\mathrm{CO}_{2}$ laser, where $I_{0}\left(\mathrm{~W} \mathrm{~cm}^{-2}\right)$ is the laser intensity at the surface of the droplet and $I$ is the intensity after passing through a path length $l$ of the liquid.

In the present ATR-FTIR accessory, the IR beam is incident on a $\mathrm{ZnSe}$ internal-reflection element at angle $\theta$ of $45^{\circ}$. The ATR-FTIR absorbance spectrum of JP-10 in the relevant wavelength region is shown in Figure $\mathrm{S} 1$. The absorbance $A$ is defined by:

$$
A=-\log _{10}\left(\frac{I}{I_{0}}\right)
$$

where $I$ and $I_{0}$ denote here the incident and reflected intensities, respectively. The wavelength range output by the $\mathrm{CO}_{2}$ laser from 10.57 to $10.63 \mu \mathrm{m},{ }^{1}$ which corresponds to a wavenumber range of 946.1 to $940.7 \mathrm{~cm}^{-1}$, is included in Figure S1. Figure S1 shows that the wavelength range of the laser overlaps with an absorption peak in JP-10 at $945 \mathrm{~cm}^{-1}$, which was assigned to a ring breathing mode in Ref. [2]. The absorbance at the center laser wavelength of $10.60 \mu \mathrm{m}$ (or $943.4 \mathrm{~cm}^{-1}$ ) is:

$$
A(10.60 \mu \mathrm{m})=0.0438
$$

The mean absorbance averaged over the 946.1 to $940.7 \mathrm{~cm}^{-1}$ wavenumber range has a similar value of 0.0451 .

The amplitude of electric field for the so-called evanescent wave within the sample decreases exponentially according to:

$$
E=E_{0} e^{-z / d_{p}}
$$

where $z$ is the perpendicular distance from the sample-ZnSe boundary and the penetration depth $d_{p}$ is defined by:

$$
d_{p}=\frac{\lambda}{2 \pi n_{1} \sqrt{\sin ^{2} \theta-n_{21}^{2}}}
$$

with

$$
\begin{aligned}
& \lambda=\text { wavelength of laser in vacuum } \approx 10.6 \mu \mathrm{m} \\
& n_{1}=\text { refractive index of } \mathrm{ZnSe}=2.39 \text { (Ref. [4]) } \\
& n_{2}=\text { refractive index of } \mathrm{JP}-10 \approx 1.5 \\
& n_{21}=n_{2} / n_{1} \\
& \theta=\text { incident angle }=45^{\circ}
\end{aligned}
$$

Hence

$$
d_{p}=2.17 \mu \mathrm{m}
$$

To relate the penetration depth $d_{p}$ to the path length $l$ in standard transmission experiments (see equation (S1)), the concept of an effective thickness $d_{e}$ was introduced. ${ }^{3}$ The effective thickness is the path length in a standard transmission experiment that would produce the same absorbance as the ATR accessory with one internal reflection, that is,

$$
\text { Reflectivity } R=\frac{I}{I_{0}}=e^{-\alpha d_{e}}
$$




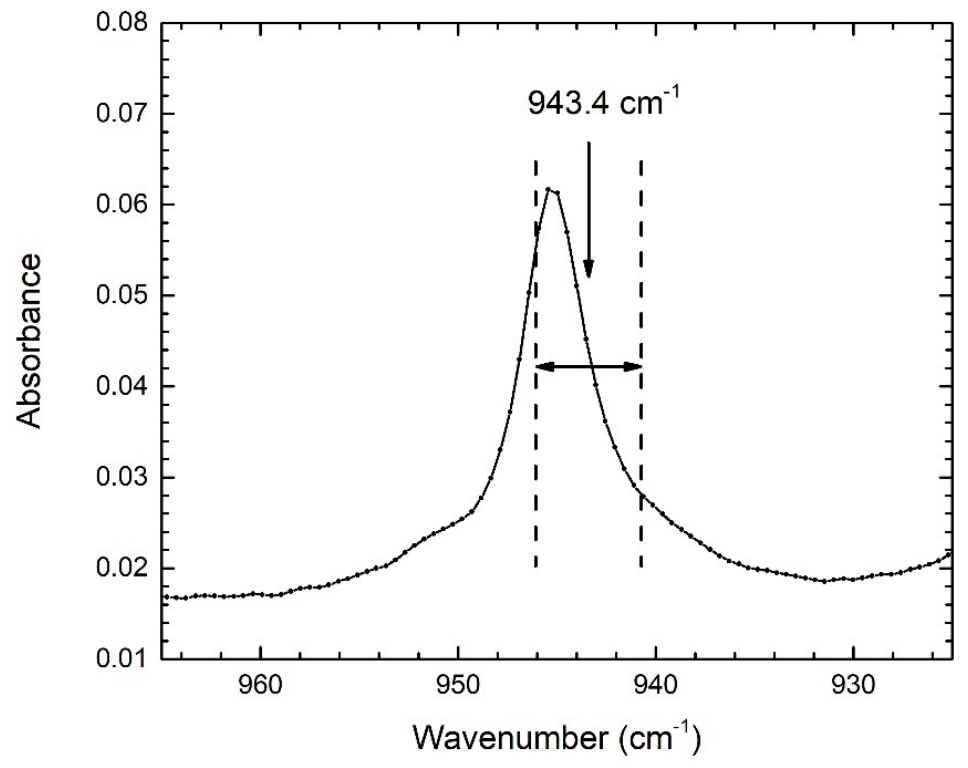

Figure S1. ATR-FTIR absorption spectrum of JP-10 with a spectral resolution of $1 \mathrm{~cm}^{-1}$ in the wavenumber region of the $\mathrm{CO}_{2}$ laser beam. The center laser wavelength is indicated by the arrow and the wavelength range is shown by the dotted lines.

For the randomly polarized IR beam produced by an FTIR spectrometer, the relationship between the effective thickness $d_{e}$ and the penetration depth $d_{p}$ is:

$$
d_{e}=\frac{n_{21} \cos \theta}{1-n_{21}{ }^{2}}\left(1+\frac{2 \sin ^{2} \theta-n_{21}{ }^{2}}{\left(1+n_{21}{ }^{2}\right) \sin ^{2} \theta-n_{21}{ }^{2}}\right) d_{p}
$$

which at the wavelength of $10.6 \mu \mathrm{m}$ gives

$$
d_{e}=4.76 \mu \mathrm{m}
$$

Therefore, the absorption coefficient of JP-10 at $10.6 \mu \mathrm{m}$ is

$$
\alpha=\frac{A \log _{e} 10}{d_{e}}=2.12 \times 10^{4}
$$

Thus, the $10.6 \mu \mathrm{m}$ laser beam is strongly attenuated by the JP-10 and the intensity decreases to $1 / e$ of the value at the surface in a distance, $1 / \alpha$, of approximately $50 \mu \mathrm{m}$.

To determine how the Al particles affect the attenuation of the laser beam within the droplet, the reflectivity $R$ is required at $10.6 \mu \mathrm{m}$. Unoxidized Al has the reflectivity of: ${ }^{5}$

$$
R_{A l}(10.6 \mu \mathrm{m})=0.988
$$

When exposed to air, aluminum forms an aluminum oxide surface layer consisting of amorphous $\mathrm{Al}_{2} \mathrm{O}_{3}$ and $\gamma-\mathrm{Al}_{2} \mathrm{O}_{3}$ with a thickness of approximately $5 \mathrm{~nm} .{ }^{6}$ The reflectance of such an oxide layer formed on an aluminum mirror has been measured by Querry ${ }^{6}$ with the result:

$$
R_{\mathrm{Al}_{2} \mathrm{O}_{3}}(10.6 \mu \mathrm{m})=0.972
$$

Thus $\mathrm{Al}$, amorphous $\mathrm{Al}_{2} \mathrm{O}_{3}$, and $\gamma-\mathrm{Al}_{2} \mathrm{O}_{3}$ are highly reflective to the $\mathrm{CO}_{2}$ laser beam. Another relevant consideration is the typical separation, $S$, of the $\mathrm{Al}$ particles within the droplet, which for an $\mathrm{Al}$ concentration of $2 \%$ by wt. and particle diameters of, for example, $100 \mathrm{~nm}$ and $8.8 \mu \mathrm{m}$ are:

$$
\begin{aligned}
& S(100 \mathrm{~nm})=420 \mathrm{~nm}, \\
& S(8.8 \mu \mathrm{m})=37 \mu \mathrm{m}
\end{aligned}
$$


Consequently, there are very few larger diameter $\mathrm{Al}$ particles in the $50 \mu \mathrm{m}$ outer layer relative to the smaller diameter particles from which the $\mathrm{CO}_{2}$ laser beam can scatter.

The relevant physical factors discussed above can now be combined to understand the behavior of the $10.6 \mu \mathrm{m}$ laser beam as it propagates through a JP-10 droplet containing micron- to nanosized $\mathrm{Al}$ particles. The $\mathrm{CO}_{2}$ laser beam irradiates a spot with a diameter $\left(1 / e^{2}\right)$ of $0.2 \mathrm{~mm}$ on the surface of the droplet, and the intensity decreases to $1 / e$ of the value at the surface in a distance of approximately $50 \mu \mathrm{m}$. The JP-10 consequently absorbs the laser beam within a thin outer layer of the droplet, which has typical dimensions of $2.7 \mathrm{~mm} \times 1.2 \mathrm{~mm}$. The Al particles are highly reflective at $10.6 \mu \mathrm{m}$ and therefore scatter the laser beam within this outer layer, and most of the scattered radiation will subsequently be absorbed by the JP-10. A small fraction of the laser beam will backscatter out of the droplet, however, thereby reducing the total power absorbed. Another consequence of backscattering might be to concentrate the absorption of the laser beam within a smaller volume near the surface, which could increase the probability of igniting the JP-10 droplet or vaporizing the JP-10 together with the associated ejection of the Al particles. The effective cross-sectional area presented to the laser beam in the $50 \mu \mathrm{m}$ outer layer is larger for the reduced particle diameters ((see equations (S13)) and, hence, the backscattering effect is significantly greater. The increased backscattering from the smaller $\mathrm{Al}$ particles could cause the laser beam to be absorbed in a smaller volume near the surface of the droplet than for the larger particles, and so might lead to the lower minimum ignition conditions discussed in section 3.2. The model also shows that the $\mathrm{CO}_{2}$ laser beam is mainly absorbed by the JP-10, which, in turn, heats the $\mathrm{Al}$ particles by thermal conduction rather than the heat transfer occurring from the Al particles to the JP-10.

\section{Effects of Size and Prestressing of Aluminum Particles on the Ultraviolet-Visible (UV-Vis) emission spectra produced by igniting levitated JP-10 Droplets}

In Figure S2, UV-Vis emission spectra are shown for the untreated particles with diameters of 100 $\mathrm{nm}, 500 \mathrm{~nm}, 1.6 \mu \mathrm{m}$, and $8.8 \mu \mathrm{m}$ to search for differences caused by variations in the particle size. Clearly, there are large variations between the four spectra. The variations for repeated measurements of a given sample type were equally large, however, which are caused by the stochastic nature of the ignition process and small, unavoidable changes in the experimental conditions. In particular, the ignition temperature, as determined from the black-body fits, varied between the limits of $1900 \mathrm{~K}$ and $2900 \mathrm{~K}$ for a given sample type. The structure was observed to grow in amplitude and change in shape as the temperature increased. The black-body temperatures for the $100 \mathrm{~nm}, 500 \mathrm{~nm}, 1.6 \mu \mathrm{m}$, and $8.8 \mu \mathrm{m}$-diameter particles in Figure S2 were $2610 \mathrm{~K}, 2670$ $\mathrm{K}, 2130 \mathrm{~K}$, and $2350 \mathrm{~K}$, respectively. Therefore, the differences between the spectra in Figure S2 cannot be used to determine how the particle diameter affects the emission processes. To maximize the amplitude of the emission bands, the UV-Vis spectra were collected for the highest flame temperatures reached; therefore, the flame temperatures for the UV-Vis spectra are much higher than the typical values discussed in section 3.3. UV-Vis emission spectra for the $100 \mathrm{~nm}$-diameter untreated, prestressed, and superquenched nanoparticles are displayed in Figure S3 to determine whether the different stress treatments influence the spectra. As for the particle diameter, differences caused by the stress treatment cannot be discerned above the stochastic variations. The black-body temperatures for the untreated, prestressed, and superquenched nanoparticles in Figure S3 were $2610 \mathrm{~K}, 2320 \mathrm{~K}$, and $2930 \mathrm{~K}$, respectively. 

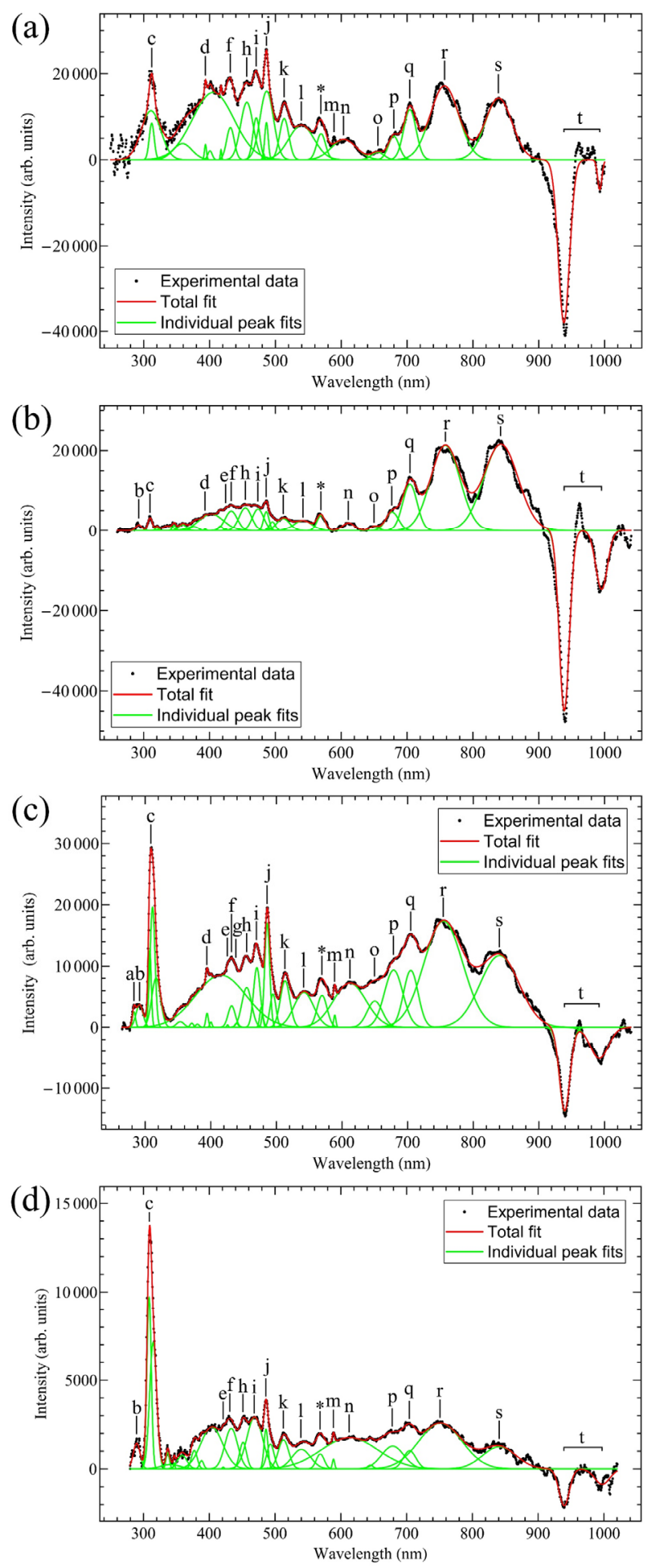

Figure S2. Comparison between the UV-Vis emission spectra for the untreated aluminum particles with diameters of a) $8.8 \mu \mathrm{m}$, b) $1.6 \mu \mathrm{m}$, c) $500 \mathrm{~nm}$, and d) $100 \mathrm{~nm}$. The black-body backgrounds have been subtracted from the spectra. 
(a)

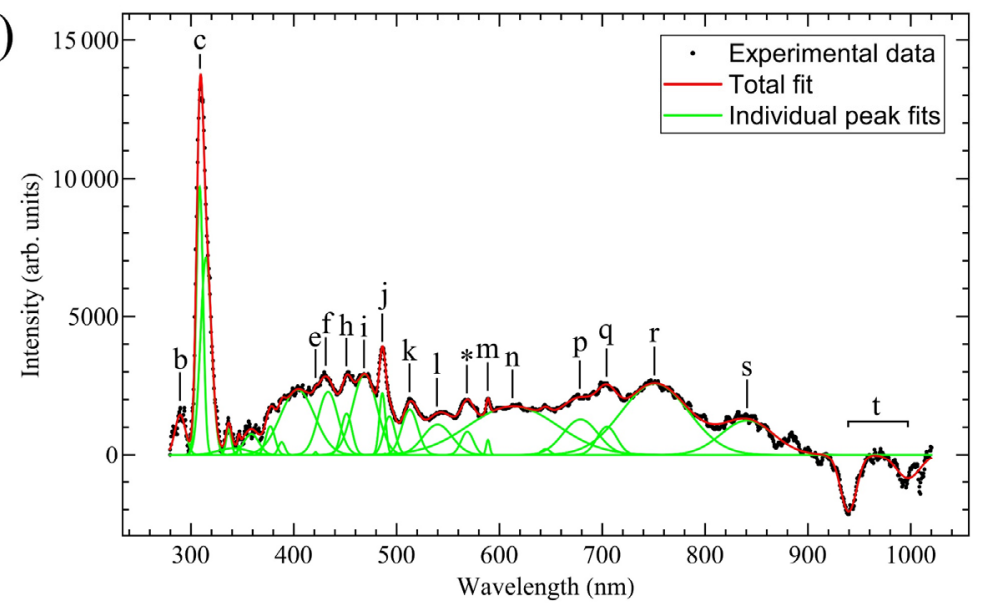

(b)

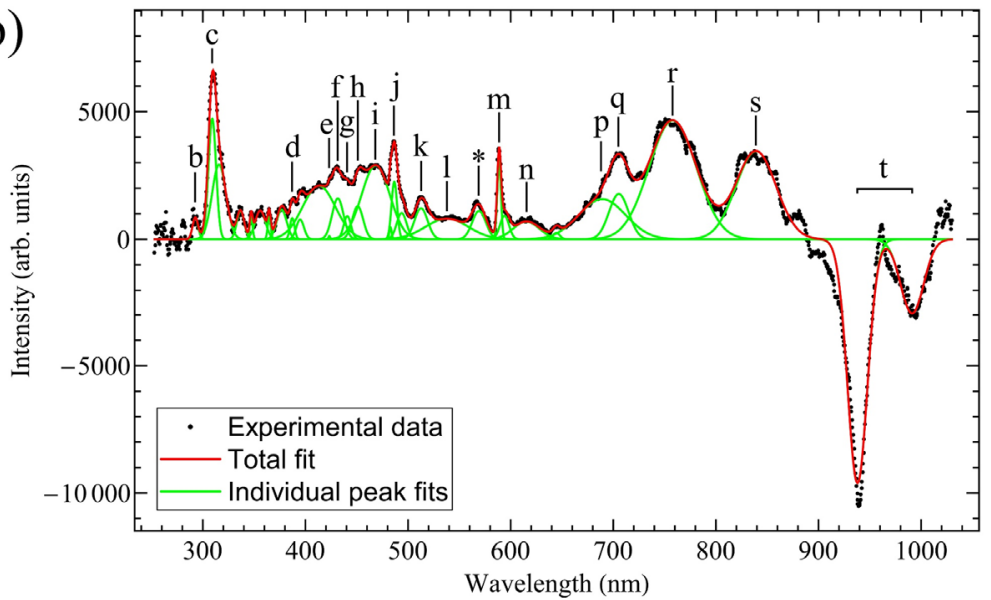

(c)

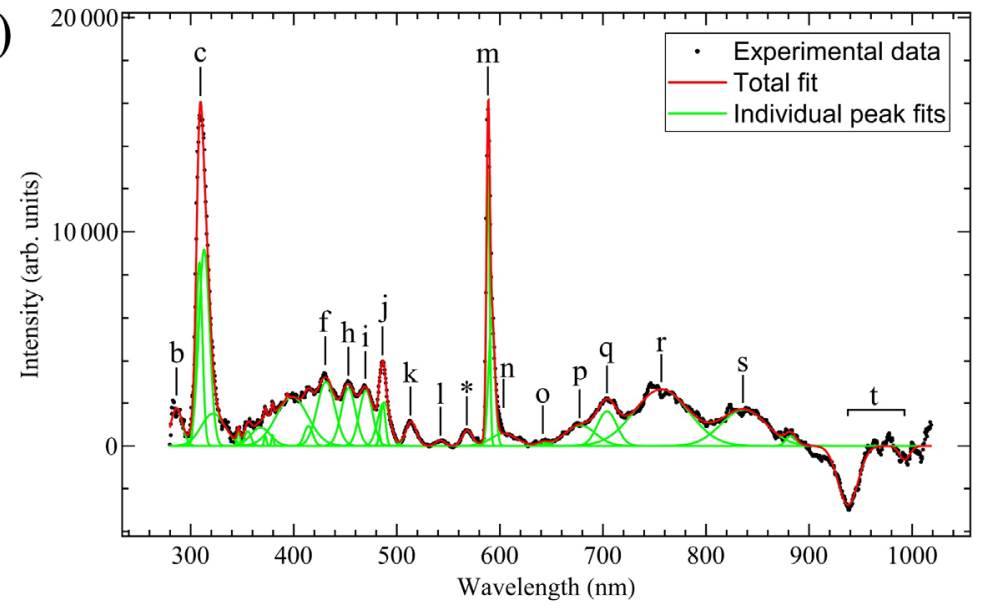

Figure S3. Comparison between the UV-Vis emission spectra for the a) untreated, b) prestressed, and c) superquenched $100 \mathrm{~nm}$-diameter aluminum nanoparticles. The black-body backgrounds have been subtracted from the spectra. 


\section{High-Speed Optical Videos of Igniting JP-10 Droplets Containing AI Nanoparticles with Different Diameters and Types of Stress Treatment}

Movie M1. High-speed video of an igniting JP-10 droplet doped with $100 \mathrm{~nm}$-diameter untreated Al particles.

Movie M2. High-speed video of an igniting JP-10 droplet doped with $100 \mathrm{~nm}$-diameter prestressed Al particles.

Movie M3. High-speed video of an igniting JP-10 droplet doped with $100 \mathrm{~nm}$-diameter superquenched Al particles.

Movie M4. High-speed video of an igniting JP-10 droplet doped with $250 \mathrm{~nm}$-diameter untreated Al particles.

Movie M5. High-speed video of an igniting JP-10 droplet doped with $250 \mathrm{~nm}$-diameter prestressed Al particles.

Movie M6. High-speed video of an igniting JP-10 droplet doped with $250 \mathrm{~nm}$-diameter superquenched $\mathrm{Al}$ particles.

Movie M7. High-speed video of an igniting JP-10 droplet doped with $500 \mathrm{~nm}$-diameter untreated Al.

Movie M8. High-speed video of an igniting JP-10 droplet doped with $500 \mathrm{~nm}$-diameter prestressed Al particles.

Movie M9. High-speed video of an igniting JP-10 droplet doped with $500 \mathrm{~nm}$-diameter superquenched $\mathrm{Al}$ particles.

Movie M10. High-speed video of an igniting JP-10 droplet doped with $1.6 \mu$ m-diameter untreated Al particles.

Movie M11. High-speed video of an igniting JP-10 droplet doped with $1.6 \mu \mathrm{m}$-diameter prestressed Al.

Movie M12. High-speed video of an igniting JP-10 droplet doped with $1.6 \mu \mathrm{m}$-diameter superquenched Al particles.

Movie M13. High-speed video of an igniting JP-10 droplet doped with $8.8 \mu \mathrm{m}$-diameter untreated $\mathrm{Al}$ particles. 


\section{References}

( 1) Firestar v40 Operator's Manual

(https://www.synrad.com/resources/libraries/manuals-1).

(2) Lucas, M.; Brotton, S. J.; Min, A.; Pantoya, M. L.; Kaiser, R. I., Oxidation of levitated exotetrahydrodicyclopentadiene droplets doped with aluminum nanoparticles. J. Phys. Chem. Lett. 2019, 10, 5756-5763.

( 3) Harrick, N. J., Internal reflection spectroscopy. Interscience Publishers: New York, 1967; p xiv, $327 \mathrm{p}$.

(4) Amotchkina, T.; Trubetskov, M.; Hahner, D.; Pervak, V., Characterization of e-beam evaporated $\mathrm{Ge}, \mathrm{YbF}_{3}, \mathrm{ZnS}$, and $\mathrm{LaF}_{3}$ thin films for laser-oriented coatings. Appl. Opt. 2020, 59, A40-A47.

( 5) Rakic, A. D., Algorithm for the determination of intrinsic optical constants of metal films: application to aluminum. Appl. Opt. 1995, 34, 4755-4767.

( 6) Querry, M. R., Optical constants. Contractor Report CRDC-CR-85034. 1985

(https://apps.dtic.mil/docs/citations/ADA158623). 